\title{
Risk Factors for Unexpected Removal of Peripherally Inserted Central Catheters and Proper Duration of the Catheter Maintenance
}

\author{
Narang Lee, M.D., Hyun-Dong Chae, M.D., In-Hwan Kim, M.D. \\ Department of Surgery, Daegu Catholic University School of Medicine, Daegu, Korea
}

\begin{abstract}
Purpose: Despite the advantages of a peripherally inserted central catheter (PICC), many complications have led to the unexpected removal of catheters. On the other hand, there are no guidelines for the duration of PICC maintenance. This study analyzed the risk factors for the unexpected removal of PICC to suggest guidelines for the duration of catheter maintenance.

Materials and Methods: Among 520 patients who underwent PICC insertion from January 2014 to December 2015, 407 were included. Unexpected removal was observed in 95 patients. Univariate and multivariate analyses were performed to evaluate the risk factors for unexpected removal. The changing pattern of the probability of unexpected removal was analyzed by change point analysis.

Results: Malignancy $(\mathrm{OR}=4.498,95 \% \mathrm{Cl}=2.49 \sim 8.125)$ and ICU hospitalization (OR=4.218, 95\% Cl=1.694 10.505) were significant risk factors for the unexpected removal of PICC. The left arm (OR=0.279, $95 \% \mathrm{Cl}=0.143 \sim 0.544)$ and basilic vein $(\mathrm{OR}=0.323,95 \% \mathrm{Cl}=0.192 \sim 0.545)$ were associated with a lower probability of unexpected removal compared to the right arm and brachial vein, but selection bias could exist in the arm side and vein. Change-point analysis revealed a rapid increase in the probability of unexpected removal after 54 catheter days.

Conclusion: This study suggests the removal or exchange of PICC before 54 catheter days to minimize serious complications. More attention is needed for patients with malignancies and ICU stays. (Surg Metab Nutr 2020;11:27-33)
\end{abstract}

Key Words: Central venous catheterization, Peripherally inserted central catheterization, Catheter related bloodstream infection, Deep vein thrombosis, Change point analysis

\section{INTRODUCTION}

Central venous catheters (CVCs) are frequently needed for hospitalized patients to establish a stable intravenous route for drug administration, fluid therapy, or nutritional support.[1] The use of peripherally inserted central catheters (PICCs) have been dramatically increased over the past decade as a safer and effective alternative for conventional CVCs, which are directly inserted into the internal jugular or subclavian vein.[2] The guideline of the European Society of Parenteral and Enteral Nutrition
(ESPEN) recommends that conventional CVCs should be limited to short-term use. When the duration of catheter placement is estimated to be longer than a month, PICC is one of the choice of venous access. [3]

The PICC is a long (about $40 \mathrm{~cm}$ ) venous catheter that is inserted into upper limb vein with its tip located at the junction between the superior vena cava and right atrium. Many clinicians believed that PICCs have many advantages over conventional CVCs including easier and safer placement, lower risk of infectious complication. Several studies had reported that lower incidence of

Received April 1, 2020. Accepted May 15, 2020.

Correspondence to: In-Hwan Kim, Department of Surgery, Daegu Catholic University School of Medicine, 33 Duryugongwon-ro 17-gil, Nam-gu, Daegu 42472, Korea

Tel: +82-53-650-4429, Fax: +82-53-624-7185, E-mail: kih2yk@cu.ac.kr

(c) This is an open access article distributed under the terms of the Creative Commons Attribution Non-Commercial License (http://creativecommons. org/licenses/by-nc/4.0) which permits unrestricted non-commercial use, distribution, and reproduction in any medium, provided the original work is properly cited. 
catheter related infection in PICCs. [4,5]

Despite these advantages of PICCs, there are still many complication which lead to unexpected removal of catheters, and sometimes serious complication including catheter related sepsis and deep vein thrombosis (DVT) can be critical to clinical course of patients. Recently, some researchers said that the infection rate of PICCs and conventional CVCs are not significantly different.[6] However, PICC-related complications are not well understood because studies were not homogenous and there is no consensus on preventing these complications. Furthermore, although prolonged duration of catheter placement increases the risk of major complications, there is no guideline for the safe duration of PICC maintenance.[7,8] Therefore, better understanding of the complications and the guideline for the duration is necessary for the safer use of PICCs.

We conducted this study to evaluate the risk factors for complications that lead to unexpected removal, and to suggest a proper maintenance period of PICC by analyzing the pattern of occurring the event of unexpected removal.

\section{MATERIALS AND METHODS}

\section{Procedure for PICC insertion}

All procedures for PICC insertion were performed in an operating room by a single surgeon. In the supine position, the axilla to forearm of an upper extremity was prepared with $2 \%$ chlorohexidine in alcohol and draped with a sterile manner. The upper arm vein was evaluated by ultrasonography. The basilic vein was chosen first to avoid injury of the median nerve or brachial artery. When this vein was inappropriate because of small diameter less than $4 \mathrm{~mm}$ or presence of thrombus inside the vein, the brachial vein was used for puncture. [9] The left arm was selected predominantly since most of the patients were right-handed. When a patient was left-handed or when the left arm could not be accessed, the right arm was chosen. After local anesthesia was taken, ultrasonography-guided vein puncture was performed using a micro-needle. A guide-wire was introduced through the micro-needle, and intraoperative radiography was used to locate the tip of the wire at the junction of the superior vena cava and right atrium. After proper length of catheter was calculated using the length of guide-wire, the catheter was prepared and inserted. The catheter tip position was confirmed again by intraoperative radiography.

\section{Patients and study design}

This retrospective observational study was conducted from 520 hospitalized patients who underwent PICC insertion from January 2014 to December 2015 in Daegu Catholic University Hospital. We excluded 113 patients because of accidental removal of catheters $(n=27)$, transfer to another hospital $(n=20)$, lost to follow-up $(n=48)$, change vascular access to an implantable port $(n=13)$, and death not due to catheter-related complications $(\mathrm{n}=5)$.

We classified 407 patients into the unexpected removal group ( $n=95)$ and success to maintain group $(n=312)$. Unexpected removal was defined as catheter removal caused by any complication which include not only serious problems but also minor complications. Complications leading to unexpected removal were blood stream infection, fever, DVT, catheter occlusion, arm swelling, phlebitis, and insertion site pain. Patients whom the catheter was maintained to the end of the planned periods and removed without any complication comprised the success to maintain group, regardless of duration of catheter days.

Baseline characteristics and risk factors are compared between the two groups and risk factors were evaluated by univariate and multivariate analysis. To find the specific point of increasing probability, change pattern of occurring removal events was evaluated according to days of catheter use in 95 patients in the unexpected removal group. This study was approved by the institutional review board of Daegu Catholic University Hospital (CR-18-132). 


\section{Statistical analysis}

Summaries of demographic and clinical characteristics were performed using descriptive statistics. The values of means and standard deviations (SD) are presented for quantitative variables, and values of frequency and percent for qualitative variables. Risk factor of unexpected removal was analyzed by univariate and multivariate analysis using binary simple logistic regression and binary multiple logistic regression. $P$ values less than 0.05 were considered to indicate statistical significance. Plot for cumulative probability of unexpected removal according to the catheter days was analyzed using change point analysis and semi parametric regression analysis. IBM SPSS ver. 19.0 was used for the analysis (IBM, Inc., Armonk, NY).

\section{RESULTS}

\section{Patient characteristics}

A total of 407 patients underwent PICC insertion. These included 95 patients in the unexpected removal group and 312 patients in the success to maintain group. Baseline characteristics of patients are shown in Table 1. Mean age of total patients was 66.3 years with $52.3 \%$ male and $47.7 \%$ female. There were no significant differences of age and sex between the two groups ( $\mathrm{P}=0.530$ and 0.592 , respectively).

Total catheter days were 30.993 days (mean: 76.2 days, SD: 49.8). Mean catheter days in the unexpected removal group was 58.6 days (SD: 19.1 ) and 81.5 days (SD: 51.2 ) in the success to maintain group. Among all patients, 183 patients (45.0\%) had malignant disease, 37 (9.1\%) were in the intensive care unit (ICU), and 281 (69.0\%) had been supplied total parenteral nutrition (TPN) through PICC. In characteristics of PICC, the left arm, basilic vein, and

Table 1. Baseline characteristics of patients with PICC

\begin{tabular}{|c|c|c|c|}
\hline & \multicolumn{3}{|c|}{ Group } \\
\hline & Unexpected removal (n=95) & Success to maintain $(n=312)$ & Total $(n=407)$ \\
\hline Age, mean/(SD) & $67.1(11.8)$ & $66.1(14.4)$ & $66.3(13.7)$ \\
\hline \multicolumn{4}{|l|}{ Sex } \\
\hline Male & $52(54.7 \%)$ & $161(51.6 \%)$ & $213(52.3 \%)$ \\
\hline Female & $43(45.3 \%)$ & $151(48.4 \%)$ & $194(47.7 \%)$ \\
\hline \multicolumn{4}{|l|}{ Disease and condition } \\
\hline Hypertension & $23(24.1 \%)$ & $82(26.3 \%)$ & $105(25.8 \%)$ \\
\hline Diabetes & $21(22.1 \%)$ & $54(17.3 \%)$ & $75(18.4 \%)$ \\
\hline Malignancy & $68(71.6 \%)$ & 115 (36.9\%) & $183(45.0 \%)$ \\
\hline ICU hospitalization & $20(21.1 \%)$ & $17(5.5 \%)$ & 37 (9.1\%) \\
\hline Mechanical ventilation & $6(6.3 \%)$ & $6(1.9 \%)$ & $12(3.0 \%)$ \\
\hline \multicolumn{4}{|l|}{ Use of PICC } \\
\hline Chemotherapy & $23(24.2 \%)$ & $48(15.4 \%)$ & $71(17.4 \%)$ \\
\hline Antibiotics & $30(31.6 \%)$ & $93(29.8 \%)$ & $123(30.2 \%)$ \\
\hline TPN & $62(65.3 \%)$ & $219(70.2 \%)$ & $281(69.0 \%)$ \\
\hline Intermittent use & $9(9.5 \%)$ & $19(6.1 \%)$ & $28(6.9 \%)$ \\
\hline \multicolumn{4}{|l|}{ Characteristics of PICC } \\
\hline \multicolumn{4}{|l|}{ Side of arm } \\
\hline Left arm & $76(80.0 \%)$ & $276(88.5 \%)$ & $352(86.5 \%)$ \\
\hline Right arm & $19(20.0 \%)$ & $36(11.5 \%)$ & $55(13.5 \%)$ \\
\hline \multicolumn{4}{|l|}{ Punctured vein } \\
\hline Basilic vein & $46(48.4 \%)$ & $228(73.1 \%)$ & $274(67.3 \%)$ \\
\hline Brachial vein & $49(51.6 \%)$ & $84(26.9 \%)$ & $133(32.7 \%)$ \\
\hline \multicolumn{4}{|l|}{ Number of lumen } \\
\hline Double lumen & $80(84.2 \%)$ & $281(90.1 \%)$ & $361(88.7 \%)$ \\
\hline Triple lumen & 15 (15.8\%) & 31 (9.9\%) & $46(11.3 \%)$ \\
\hline Catheter days, mean (day)/(SD) & $58.6(19.1)$ & $81.5(51.2)$ & 76.2 (49.8) \\
\hline
\end{tabular}


double lumen catheters were more commonly used than the right arm, brachial vein, and triple lumen (Table 1).

Complications causing unexpected removal are summarized in Table 2. The most common cause of unexpected removal was catheter occlusion (29.5\%), followed by blood stream infection with bacteremia confirmed by blood culture (21.1\%), phlebitis (16.8\%), fever without evidence of bacteremia (13.7\%), arm swelling (8.4\%), pain (7.4\%), and DVT (3.2\%). Incidence of blood stream infection was 20 per 407 patients (4.9\%), 0.64 per 1.000 catheter days, and DVT was 3 per 407 patients (0.7\%), 0.1 per 1.000 catheter days.

\section{Risk factor for unexpected removal of PICC}

Univariate analysis for risk factor of unexpected removal was performed for 13 variables using binary simple logistic regression. Malignancy (Odds ratio [OR]: 4.314, 95\% confidence interval [CI]: 2.612 7.125), chemotherapy (OR: 1.757, 95\% CI: 1.002 3.080), ICU hospitalization (OR: 4.627, 95\% CI: 2.311 9.267), and mechanical ventilation (OR: 3.438, 95\% CI: 1.082 10.923) were associated with the risk of unexpected removal (Table 3). Left arm (OR: 0.522, 95\% CI: 0.283 0.961) was associated with decreasing unexpected removal compared with the right arm, and the basilic vein (OR: 0.346, 95\% CI: 0.215 0.555) was also associated with less likely occurring unexpected removal compared with brachial vein (Table 3).

In multivariate analysis using binary multiple logistic regression, malignancy (OR: 4.498, 95\% CI: 2.49 8.125) and ICU hospitalization (OR: 4.218, 95\% CI: 1.694 10.505) were significant risk factors for unexpected removal of PICC. Left arm (OR: 0.279, 95\% CI: 0.143

Table 2. Causes of unexpected removal

\begin{tabular}{lc}
\hline \multicolumn{1}{c}{ Cause } & $(\mathrm{n}=95)$ \\
\hline Blood stream infection & $20(21.1 \%)$ \\
Fever & $13(13.7 \%)$ \\
Deep vein thrombosis & $3(3.2 \%)$ \\
Catheter occlusion & $28(29.5 \%)$ \\
Arm swelling & $8(8.4 \%)$ \\
Phlebitis & $16(16.8 \%)$ \\
Pain on insertion site & $7(7.4 \%)$ \\
\hline
\end{tabular}

0.544 ) and basilic vein (OR: $0.323,95 \%$ CI: 0.192 0.545) were still remained as significant preventative factors in multivariate analysis (Table 4).

\section{Change point analysis for the probability of unexpected removal}

Ninety-five patients with unexpected removal of PICC were further analyzed with the graph of cumulative events to evaluate the occurring pattern of unexpected removal and to detect a specific change point. Fig. 1.

\begin{tabular}{|c|c|c|c|}
\hline Variable & OR & $95 \% \mathrm{Cl}$ & $\mathrm{P}$-value \\
\hline Hypertension & 0.896 & $(0.526,1.527)$ & .686 \\
\hline Diabetes & 1.356 & $(0.769,2.389)$ & .292 \\
\hline Malignancy & 4.314 & $(2.612,7.125)$ & $.000^{*}$ \\
\hline Chemotherapy & 1.757 & $(1.002,3.080)$ & $.049^{*}$ \\
\hline ICU hospitalization & 4.627 & $(2.311,9.267)$ & $.000 *$ \\
\hline Mechanical ventilation & 3.438 & $(1.082,10.923)$ & $.036^{*}$ \\
\hline Major surgery & 0.917 & $(0.450,1.869)$ & .811 \\
\hline Antibiotics & 1.087 & $(0.662,1.785)$ & .742 \\
\hline TPN & 0.798 & $(0.490,1.298)$ & .363 \\
\hline \multicolumn{4}{|l|}{ Side of arm } \\
\hline Right arm & 1 & Ref & Ref \\
\hline Left arm & 0.522 & $(0.283,0.961)$ & $.037^{*}$ \\
\hline \multicolumn{4}{|l|}{ Punctured vein } \\
\hline Brachial vein & 1 & Ref & Ref \\
\hline Basilic vein & 0.346 & $(0.215,0.555)$ & $.000^{*}$ \\
\hline Intermittent use & 1.614 & $(0.705,3.696)$ & .258 \\
\hline \multicolumn{4}{|l|}{ Number of lumen } \\
\hline Triple lumen & 1 & Ref & Ref \\
\hline Double lumen & 0.588 & $(0.303,1.144)$ & .118 \\
\hline
\end{tabular}

Table 4. Multivariate analysis for the risk factor of unexpected removal of PICC

\begin{tabular}{cccc}
\hline Variable & OR & $95 \% \mathrm{Cl}$ & P-value \\
\hline Malignancy & 4.498 & $(2.49,8.125)$ & $.000^{*}$ \\
ICU hospitalization & 4.218 & $(1.694,10.505)$ & $.002^{*}$ \\
$\begin{array}{l}\text { Side of arm } \\
\text { Right arm }\end{array}$ & 1 & Ref & Ref \\
$\quad$ Left arm & 0.279 & $(0.143,0.544)$ & $.000^{*}$ \\
Punctured vein & & & \\
Brachial vein & 1 & Ref & Ref \\
Basilic vein & 0.323 & $(0.192,0.545)$ & $.000^{*}$ \\
\hline
\end{tabular}

*Statistically significant with $\mathrm{P}<0.05$.

$\mathrm{PICC}=$ peripherally inserted central catheter; $\mathrm{Cl}=$ confidence interval; $\mathrm{ICU}=$ intensive care unit. 


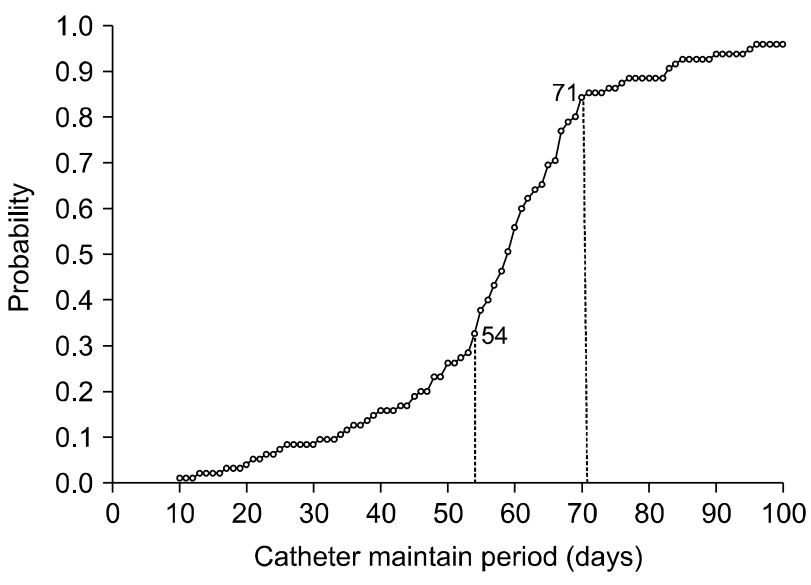

Fig. 1. Changes in cumulative probability of unexpected removal of PICC according to the catheter days. The cumulative probability plot changes rapidly from 54 days to 71 days based on change point analysis and semi parametric regression analysis.

showed the change in cumulative probability of unexpected removal of PICC according to the catheter days. There was rapid increment of probability from 54 to 71 days using change point analysis and semi parametric regression analysis. This result represents that, after 54 days from the day of PICC insertion, there was a markedly increased tendency of complications causing unexpected removal.

\section{DISCUSSION}

The first successful experience of PICC insertion was reported in 1975 [10]. After the second millennium, the use of PICC has been significantly increased with the advantage over conventional CVC including easier and safer insertion, less pain, and increased patient satisfaction.[2] Above all of this advantages, the most important factor affecting the popularity of PICCs is clinicians' belief that PICCs have less catheter-related complications, especially blood stream infections.[2] Initial studies with PICCs supported this belief with low incidence of blood stream infection (0.4 0.8 per 1000 catheter days).[11,12] Several researchers suggested that the theoretical cause of less infectiveness of PICC are low temperature and cleaner environment of the upper extremity compared to the neck area, which can help minimize bacterial growth. $[13,14]$
Recently, more complications with serious clinical problem with the patients underwent PICCs have been reported.[15-18] Ajenjo et al. [17] reported that the rate of PICC-related blood stream infections was 2.78 per 1000 catheter days, and Chopra et al. [7] reported a rate of 2.16 blood stream infection per 1000 catheter days. Several studies suggested that PICC is not safer any more than other techniques, and some study reported even higher incidence of blood stream infections and DVT associated with PICCs.[19-21] The result is agreed among most researchers that medical status such as malignancy and ICU stay is closely related to complications.[17,22,23] This study also showed that malignancy (OR: 4.498, 95\% CI: 2.49 8.125) and ICU hospitalization (OR: 4.218, 95\% CI: $1.694 \sim 10.505)$ are significant risk factors for unexpected removal.

There is lack of data from previous studies about the association between catheter-related complications and the selection of vein and arm. Sperry et al. [24] reported that laterality of PICC did not affect the incidence of thromboembolism. Liem et al. [25] reported that PICCs placed in the basilic vein were associated with two-times greater risk of DVT compared with non-basilic vein placements (3.1\% vs $1.5 \%)$. In contrast, Chopra et al. [26] reported that the selection of vein was not associated with the incidence of DVT. Several researchers also reported that selection of vein and arm was not associated with complication in their review article.[2,6] However, this study showed that the left arm (OR: 0.279, 95\% CI: $0.143 \sim 0.544$ ) and basilic vein (OR: 0.323, 95\% CI: 0.192 $0.545)$ were associated with decreasing probability of unexpected removal. Although the incidence of DVT is low in Asians and less pain and phlebitis at the non-dominant arm could be causative factors for the different results associated with basilic vein and left arm, there could also be a selection bias. Because we selected non-dominant arm and basilic vein first, the left arm and basilic vein were chosen first with the other side and vein chosen in unsuitable cases. Therefore, the size or condition of vein may have been poor in patients who underwent PICC on the right side or brachial vein in this study. 
According to previous studies, PICC related blood stream infection was ranging from 1 to 4 per 1000 catheter days, [6] and DVT rates between 4 8\%.[27] In our research, there were lower incidences of major complications (blood-stream infection: 0.64 per 1.000 catheter days, DVT: 0.7\%). These low incidences might reflect the sterile environment of the operating room; in other studies, cases have involved PICC insertion at the bed side. Additionally, PICC insertion in an operating room can be done using intraoperative radiography confirmation of catheter tip position. [28] The main reason for the low incidence of major complication in this study is thought to be the large number of PICC removals due to minor complications. For example, only $21.1 \%$ and $3.2 \%$ of unexpected removals were due to bloodstream infection and DVT. However, direct comparison of complication is worthless, because most studies with PICCs are not uniform and the results are in wide variety. The variance of results might be caused by different environment and methods for PICC insertion. Moreover, because there is still no recommendation for the duration of PICC maintenance, different policies of catheter maintenance among centers can lead to different results. Therefore, a proper guideline for duration of PICC maintenance is important not only for patient care, but also for the qualified research.

Proper guideline for duration of PICC maintenance is necessary to achieve both of safety and cost effectiveness. Most recent studies about complication of PICCs focused on serious complications, such as blood-stream infection and DVT, as the risk factors, and suggested caution for high-risk patients.[29,30] But, these complications are not suitable to recommend the day of catheter removal, because removal of PICCs after development of severe complication can worsen the clinical course of patients with additional treatment. For this reason, we analyzed the patterns of unexpected removal based on any complications, regardless of their severity. In this study, probability of unexpected removal was sharply increase after 54 catheter days (Fig. 1). Based on this result, we suggest removal or exchange of PICCs before 54 cath- eter days, even if there is no evidence of catheter related complication, to minimize serious problem.

There are several limitation in this study. First, due to the limitation of a retrospective study, heterogeneous group of patients with various medical condition were included. Second, we conducted this study only for hospitalized patients. Therefore, there could be different results among outpatients or patients with home TPN. Finally, there might be a lack of evidence to determine clear guideline derived from only 95 patients with unexpected removal. However, we hope that this study can be a model for further well designed study that suggests proper recommendation for maintenance period of PICC.

In conclusion, malignancy and ICU hospitalization were significant risk factors for unexpected removal of PICC, and the probability of unexpected removal was markedly increased after 54 catheter days of PICC use. We suggest that removal or exchange of PICC should be considered before 54 catheter days, with more attention to patients with malignancy and those treated in the ICU. Further studies will be needed to validate this recommendation.

\section{ACKNOWLEDGMENTS}

This work was supported by the grant of Research Institute of Medical Science, Catholic University of Daegu (2017).

\section{REFERENCES}

1. Pittiruti M, Malerba M, Carriero C, Tazza L, Gui D. Which is the easiest and safest technique for central venous access? A retrospective survey of more than 5,400 cases. J Vasc Access 2000;1:100-7.

2. Fallouh N, McGuirk HM, Flanders SA, Chopra V. Peripherally inserted central catheter-associated deep vein thrombosis: a narrative review. Am J Med 2015;128:722-38.

3. Pittiruti $M$, Hamilton $H$, Biffi $R$, MacFie J, Pertkiewicz M; ESPEN. ESPEN guidelines on parenteral nutrition: central venous catheters (access, care, diagnosis and therapy of complications). Clin Nutr 2009;28:365-77.

4. Xu T, Kingsley L, DiNucci S, Messer G, Jeong JH, Morgan B, et al. Safety and utilization of peripherally inserted central catheters versus midline catheters at a large academic medical center. Am J Infect Control 2016;44:1458-61.

5. Sakai T, Kohda K, Konuma Y, Hiraoka Y, Ichikawa Y, Ono K, et 
al. A role for peripherally inserted central venous catheters in the prevention of catheter-related blood stream infections in patients with hematological malignancies. Int J Hematol 2014; 100:592-8.

6. Chopra V, O'Horo JC, Rogers MA, Maki DG, Safdar N. The risk of bloodstream infection associated with peripherally inserted central catheters compared with central venous catheters in adults: a systematic review and meta-analysis. Infect Control Hosp Epidemiol 2013;34:908-18.

7. Chopra V, Ratz D, Kuhn L, Lopus T, Chenoweth C, Krein S. PICC-associated bloodstream infections: prevalence, patterns, and predictors. Am J Med 2014;127:319-28.

8. Gunst M, Matsushima K, Vanek S, Gunst R, Shafi S, Frankel $H$. Peripherally inserted central catheters may lower the incidence of catheter-related blood stream infections in patients in surgical intensive care units. Surg Infect (Larchmt) 2011;12: 279-82.

9. Meyer BM. Managing peripherally inserted central catheter thrombosis risk: a guide for clinical best practice. J Assoc Vasc Access 2011;16:144-7.

10. Hoshal VL Jr. Total intravenous nutrition with peripherally inserted silicone elastomer central venous catheters. Arch Surg 1975;110:644-6.

11. Graham DR, Keldermans MM, Klemm LW, Semenza NJ, Shafer ML. Infectious complications among patients receiving home intravenous therapy with peripheral, central, or peripherally placed central venous catheters. Am J Med 1991;91:95S-100S.

12. Merrell SW, Peatross BG, Grossman MD, Sullivan JJ, Harker WG. Peripherally inserted central venous catheters. Low-risk alternatives for ongoing venous access. West J Med 1994;160: 25-30.

13. Laurenzi L, Natoli S, Benedetti C, Marcelli ME, Tirelli W, DiEmidio L, et al. Cutaneous bacterial colonization, modalities of chemotherapeutic infusion, and catheter-related bloodstream infection in totally implanted venous access devices. Support Care Cancer 2004;12:805-9.

14. Bashir MH, Olson LK, Walters SA. Suppression of regrowth of normal skin flora under chlorhexidine gluconate dressings applied to chlorhexidine gluconate-prepped skin. Am J Infect Control 2012;40:344-8.

15. Chopra V, Flanders SA, Saint S. The problem with peripherally inserted central catheters. JAMA 2012;308:1527-8.

16. Maki DG, Kluger DM, Crnich CJ. The risk of bloodstream infection in adults with different intravascular devices: a systematic review of 200 published prospective studies. Mayo Clin Proc 2006;81:1159-71.

17. Ajenjo MC, Morley JC, Russo AJ, McMullen KM, Robinson C, Williams RC, et al. Peripherally inserted central venous catheter-associated bloodstream infections in hospitalized adult patients. Infect Control Hosp Epidemiol 2011;32:125-30.
18. Safdar N, Maki DG. Risk of catheter-related bloodstream infection with peripherally inserted central venous catheters used in hospitalized patients. Chest 2005;128:489-95.

19. Periard D, Monney P, Waeber G, Zurkinden C, Mazzolai L, Hayoz D, et al. Randomized controlled trial of peripherally inserted central catheters vs. peripheral catheters for middle duration in-hospital intravenous therapy. J Thromb Haemost 2008; 6:1281-8.

20. Al Raiy B, Fakih MG, Bryan-Nomides N, Hopfner D, Riegel E, Nenninger $\mathrm{T}$, et al. Peripherally inserted central venous catheters in the acute care setting: a safe alternative to high-risk short-term central venous catheters. Am J Infect Control 2010; 38:149-53.

21. Chemaly RF, de Parres JB, Rehm SJ, Adal KA, Lisgaris MV, Katz-Scott DS, et al. Venous thrombosis associated with peripherally inserted central catheters: a retrospective analysis of the Cleveland Clinic experience. Clin Infect Dis 2002;34:117983.

22. Worth LJ, Seymour JF, Slavin MA. Infective and thrombotic complications of central venous catheters in patients with hematological malignancy: prospective evaluation of nontunneled devices. Support Care Cancer 2009;17:811-8.

23. Walshe LJ, Malak SF, Eagan J, Sepkowitz KA. Complication rates among cancer patients with peripherally inserted central catheters. J Clin Oncol 2002;20:3276-81.

24. Sperry BW, Roskos M, Oskoui R. The effect of laterality on venous thromboembolism formation after peripherally inserted central catheter placement. J Vasc Access 2012;13:91-5.

25. Liem TK, Yanit KE, Moseley SE, Landry GJ, Deloughery TG, Rumwell CA, et al. Peripherally inserted central catheter usage patterns and associated symptomatic upper extremity venous thrombosis. J Vasc Surg 2012;55:761-7.

26. Chopra V, Anand S, Krein SL, Chenoweth C, Saint S. Bloodstream infection, venous thrombosis, and peripherally inserted central catheters: reappraising the evidence. Am J Med 2012; 125:733-41.

27. Lee AY, Levine MN, Butler G, Webb C, Costantini L, Gu C, et al. Incidence, risk factors, and outcomes of catheter-related thrombosis in adult patients with cancer. J Clin Oncol 2006; 24:1404-8.

28. Vesely TM. Central venous catheter tip position: a continuing controversy. J Vasc Interv Radiol 2003;14:527-34.

29. Scott EC, Hudson KS, Trerotola S, Smith H, Porter D, Sood SL. Risk factors for venous thromboembolism in hospitalized cancer patients with central catheters. Blood 2010;116:810.

30. Bouzad C, Duron S, Bousquet A, Arnaud FX, Valbousquet L, Weber-Donat G, et al. Peripherally inserted central catheter-related infections in a cohort of hospitalized adult patients. Cardiovasc Intervent Radiol 2016;39:385-93. 